\title{
Eficácia do dipropionato de imidocarb, da enrofloxacina e do cloridrato de oxitetraciclina no tratamento de bovinos naturalmente infectados por Anaplasma marginale
}

\author{
[Efficacy of imidocarb dipropionate, enrofloxacin and oxytetracycline chlorydrate on the treatment \\ of cattle naturally infected by Anaplasma marginale] \\ L.R. Alberton ${ }^{1}$, C.F. Orlandini ${ }^{1}$, T.M. Zampieri ${ }^{1}$, A.Y. Nakamura ${ }^{1}$, D.D. Gonçalves ${ }^{1}$, \\ R. Piau Júnior ${ }^{1}$, M.M. Zaniolo ${ }^{1}$, S.T. Cardim ${ }^{2}$, O. Vidotto ${ }^{2}$, J.L. Garcia ${ }^{2}$ \\ ${ }^{1}$ Programa de pós-graduação - Universidade Paranaense -- Unipar - Umuarama, PR \\ ${ }^{2}$ Programa de pós-graduação - Universidade Estadual de Londrina (UEL) - Londrina, PR
}

\begin{abstract}
RESUMO
O agente de maior importância, em relação à anaplasmose bovina, é o Anaplasma marginale. Os principais sinais clínicos dessa enfermidade são anemia hemolítica, icterícia, dispneia, taquicardia, febre, fadiga, lacrimejamento, sialorreia, micção frequente, anorexia, perda de peso, aborto e morte. A terapia antimicrobiana é o principal protocolo terapêutico. O objetivo do presente trabalho foi avaliar a eficácia do dipropionato de imidocarb, da enrofloxacina e do cloridrato de oxitetraciclina no tratamento de bovinos leiteiros naturalmente infectados por Anaplasma marginale. Para isso, foram avaliados 48 zebuínos mestiços que apresentavam os sinais clínicos sugestivos da doença. Os animais foram submetidos à coleta de sangue para a realização de hemograma e à extração de DNA para a confirmação da presença de A. marginale, por meio da reação em cadeia pela polimerase (PCR). Os animais foram divididos em três grupos experimentais, para realização dos protocolos terapêuticos, utilizando-se dipropionato de imidocarb, oxitetraciclina e enrofloxacina. Trinta e seis animais $(75 \%)$ apresentaram reação positiva ao PCR. Os animais positivos não apresentaram diferenças significativas quanto ao hemograma e ao leucograma quando comparados com os negativos, no entanto os níveis de proteínas séricas foram inferiores nos animais positivos $(\mathrm{P}<0,05)$. Os três protocolos terapêuticos foram capazes de reduzir a infecção ao longo do tratamento $(\mathrm{P}<0,01)$, porém, após cinco dias de tratamento, a enrofloxacina apresentou maior efetividade em relação aos demais $(\mathrm{P}<0,01)$. Após o final do tratamento, nenhum protocolo foi capaz de eliminar totalmente a infecção pelo A. marginale em bovinos naturalmente infectados e manejados a campo.
\end{abstract}

Palavras-chave: Anaplasma spp., bovídeos, PCR, terapêutica

\begin{abstract}
Anaplasma marginale is the most important agent regarding cattle anaplasmosis. The main clinical signs of this disease are hemolitic anemia, jaundice, dyspnea, tachycardia, fever, fatigue, lacrimation, salivation, frequent urination, anorexia, weight loss, abortion and death. Antimicrobial therapy is the main therapeutic protocol. The aim of this paper was to assess the efficacy of this therapy frequently used in field conditions. In order to do so, 48 crossbred zebu cattle presenting suggestive clinical signs of the disease were assessed. The animals were submitted to blood sample collection to perform a CBC and DNA extraction to confirm the presence of A. marginale by the polymerase chain reaction (PCR) test. The animals were divided into three experimental groups to perform the therapeutic protocols, using imidocarb dipropionate, enrofloxacin and oxytetracycline. Thirty-six animals (75\%) presented positive reaction to PCR. The positive animals do not present significant differences in the $C B C$ and $W B C$ when compared to the negative ones. However, the serum protein levels were lower in positive animals $(P<0.05)$. All the treatments were able to reduce the infection throughout the treatment $(P<0.01)$. However, in time 1 , enrofloxacin presented greater effectiveness in relation to the other ones $(P<0.01)$. After the end of the treatment no protocol was able to totally eliminate the infection by A. marginale in cattle naturaly infected and handled on the field.
\end{abstract}

Keywords: Anaplasma spp, bovine, PCR, therapy

Recebido em 18 de agosto de 2014

Aceito em 11 de junho de 2015

E-mail: romulo@unipar.br 


\section{INTRODUÇÃO}

A anaplasmose bovina é uma infecção causada por Anaplasma spp., rickéttsia da família Anaplasmataceae, ordem Rickettsiales (Vidotto e Marana, 2001; Kocan et al., 2010). A espécie mais patogênica e de maior importância para a espécie bovina é a Anaplasma marginale. Constitui uma doença de grande importância econômica, devido aos prejuízos sanitários acarretados, afetando, principalmente, a produção bovina de muitos países (Moura et al., 2003; Felsheim et al., 2010).

A doença clínica pode apresentar-se nas formas aguda, subaguda, leve ou crônica, com anemia hemolítica, icterícia, dispneia, taquicardia, febre, fadiga, lacrimejamento, sialorreia, micção frequente, anorexia, perda de peso, aborto e morte (Kocan et al., 2010).

Em relação ao tratamento da anaplasmose bovina, alguns princípios ativos já apresentaram efeitos satisfatórios contra a infecção, como o cloridrato de oxitetraciclina (Pereira-Maia et al., 2010), o dipropionato de imidocarb (Melo e Carvalho Neta, 2009) e a enrofloxacina (Kaartinen et al., 1995). Apesar desses estudos sobre o tratamento e controle da anaplasmose, ainda existem dúvidas quanto ao tempo necessário para controlar a infecção e à duração desses efeitos contra o parasito. Adicionalmente, estudos experimentais não refletem a realidade do campo em áreas tropicais e subtropicais de difícil controle dos insetos e carrapatos que transmitem o parasito.

A enrofloxacina, apesar de muito difundida na prática veterinária, ainda foi pouco estudada contra a anaplasmose. Estudos foram conduzidos in vitro ou por meio de infecções experimentais (Facury-Filho et al., 2012). E boa parte das pesquisas envolvendo o dipropionato de imidocarb e o cloridrato de oxitetraciclina foi conduzida em animais com a infecção aguda. Além disso, ressalta-se a necessidade de se fortalecer esses experimentos com apoio de testes diagnósticos mais precisos (Ramos et al., 2009), como a técnica da reação em cadeia pela polimerase (PCR) (Vidotto e Marana, 2001). Diante disso, o objetivo do presente trabalho foi verificar os efeitos do dipropionato de imidocarb (DI), da enrofloxacina (Ef) e do cloridrato de oxitetraciclina $(\mathrm{CO})$ em animais naturalmente infectados por $A$. marginale, diagnosticados por meio da técnica da PCR com a forma crônica da doença em regime de campo.

\section{MATERIAL E MÉTODOS}

Este trabalho foi aprovado pelo Comitê de Ética em Experimentação Animal (CEPEEA) da Universidade Paranaense (Unipar), sob protocolo 22105/2012, e foi realizado em três propriedades leiteiras do município de Douradina (latitude 23 ${ }^{\circ} 22^{\prime} 51^{\prime \prime} \quad$ sul/longitude $53^{\circ} 17^{\prime} 30^{\prime \prime}$ oeste), localizado na região noroeste do estado do Paraná (PR), no período de setembro a dezembro de 2012. Foram selecionados 48 zebuínos mestiços utilizados na produção leiteira, com sinais clínicos sugestivos de anaplasmose crônica (perda de peso, hiporexia, mucosas pálidas e leve icterícia) e presença de carrapatos fixados no corpo no momento da coleta de sangue. Foram coletados, em tubos do tipo Vacutainer (com e sem anticoagulante), $10 \mathrm{~mL}$ de sangue de cada bovino, por meio de punção da veia jugular externa. As amostras de sangue com anticoagulante foram encaminhadas para a realização do hemograma completo, leucograma e dosagem das proteínas séricas totais. A extração do DNA do sangue foi realizada seguindo-se a metodologia descrita por Boom et al. (1990), e, para a confirmação da infecção por A. marginale, realizou-se a reação em cadeia pela polimerase (PCR) utilizando-se os primers: 5' TGCTTATGGCAGACATTTCCAT 3' e 5' GGGAAAGAGGACAACCACACA 3' para a visualização de um amplicon de $155 \mathrm{pb}$ (Birkenheuer et al., 2003). Após o hemograma, o leucograma, a dosagem de proteínas séricas e a confirmação inicial do diagnóstico positivo pela PCR, os animais foram divididos em três grupos experimentais e, posteriormente, submetidos a três protocolos terapêuticos distintos: grupo 1: tratamento à base de dipropionato de imidocarb a $1 \%$ (Imidocarb Pearson $^{\circledR}$, Eurofarma Laboratórios Ltda., Brasil), em dose única de $2,5 \mathrm{mg} / \mathrm{kg}$ de peso vivo, por via subcutânea (SC); grupo 2: tratamento à base de enrofloxacina a $10 \% \quad$ (Enrofloxacina $^{\circledR} 10 \%$, Tortuga Cia. Zootécnica, Brasil), na dose de $5 \mathrm{mg} / \mathrm{kg}$ de peso vivo, por via intramuscular (IM), uma vez ao dia, durante sete dias; grupo 3: tratamento à base de cloridrato de oxitetraciclina $\left(\right.$ Tormicina $^{\circledR} / \mathrm{LA}$ $20 \%$, Tortuga Cia. Zootécnica, Brasil), de longa ação, a $20 \%$, em três doses de $20 \mathrm{mg} / \mathrm{kg}$, por via intramuscular (IM), a cada 48 horas. As coletas 
de sangue foram realizadas em três etapas diferentes: imediatamente antes do tratamento, cinco dias após o tratamento e 10 dias após o tratamento, para a realização da PCR, conforme descrito acima.

Optou-se por estudar animais cronicamente infectados, já que esta é a principal forma da doença na região, bem como uma importante causa de prejuízo à pecuária em razão do caráter subclínico e do potencial disseminador desses animais para o restante do rebanho, dificultando o controle dessa enfermidade.

Os dados obtidos foram processados no software BioEstat@, versão 5.3, utilizando-se a análise de variância (ANOVA), pelo teste Q de Cochran, com nível de significância de $1 \%$ para se verificarem as diferenças entre os positivos e os negativos antes e após o tratamento. Empregouse ainda o teste exato de Fisher, em nível de significância de $5 \%$, para comparação entre os tempos e os tratamentos. Para a análise dos dados do hemograma, utilizou-se o teste de
Mann-Whitney (MW) ao nível de significância de $5 \%$.

\section{RESULTADOS}

Das 48 amostras de sangue de bovinos submetidas à PCR, $36(75,00 \%)$ amplificaram um produto de $156 \mathrm{pb}$, o que confirmou a presença de DNA de A. marginale e, consequentemente, a infecção por esse microrganismo. A Tab. 1 demonstra os resultados obtidos no hemograma dos 48 bovinos considerados positivos e negativos na PCR, sendo expressiva $(\mathrm{P}<0,05)$ a queda de proteínas totais nos animais positivos na PCR. No entanto, não foram observadas diferenças significativas, em comparação com os valores normais de referência, nos números totais de leucócitos, bastonetes, segmentados, eosinófilos, linfócitos, monócitos e basófilos.

Já a Tab. 2 demonstra a prevalência da anaplasmose pela reação da PCR, nos tempos $1 \mathrm{e}$ 2 (cinco e 10 dias após o início do tratamento, respectivamente).

Tabela 1. Comparação do exame diferencial relativo (\%) do leucograma, hemograma e proteínas plasmáticas totais dos bovinos leiteiros positivos e negativos ao exame da reação em cadeia pela polimerase (PCR) infectados naturalmente por A. marginale no município de Douradina, Paraná, Brasil, 2012

\begin{tabular}{ccccc}
\hline Células & $\begin{array}{c}\text { Amostras } \\
\text { positivas }\end{array}$ & Amostras negativas & $\begin{array}{c}\text { Teste } \\
\text { MW }\end{array}$ & $\begin{array}{c}\text { Valores de } \\
\text { referência }^{2}\end{array}$ \\
\hline Leucócitos totais & $11.288,23 \pm 3.871,99$ & $12.119,50 \pm 5.653,80$ & $\mathrm{~ns}$ & $4,0-12,0$ \\
Bastonetes & $7,88 \pm 5,29$ & $8,50 \pm 5,00$ & $\mathrm{~ns}$ & $0-3$ \\
Segmentados & $25,53 \pm 11,70$ & $25,03 \pm 9,20$ & $\mathrm{~ns}$ & $15-45$ \\
Eosinófilos & $9,88 \pm 7,03$ & $10,28 \pm 5,95$ & $\mathrm{~ns}$ & $2-20$ \\
Linfócitos & $52,29 \pm 17,58$ & $51,86 \pm 10,18$ & $\mathrm{~ns}$ & $40-75$ \\
& & & & $2-7$ \\
Monócitos & $3,70 \pm 2,34$ & $3,55 \pm 2,15$ & $\mathrm{~ns}$ & $0-2$ \\
Basófilos & $0,70 \pm 0,85$ & $0,77 \pm 1,24$ & $\mathrm{~ns}$ & 5,0 a 10,00 \\
Hemácias & $4,77 \pm 0,80$ & $4.72 \pm 0,85$ & $\mathrm{~ns}$ & $8-15$ \\
Hemoglobina & $8.81 \pm 1,18$ & $8.74 \pm 1,32$ & $\mathrm{~ns}$ & $24-46 \%$ \\
Hematócrito & $27,33 \pm 3,49$ & $26,68 \pm 4,22$ & $\mathrm{~ns}$ & 7,0 a 8,5 \\
Proteínas totais & $7,38 \pm 1,04^{\mathrm{b}}$ & $8,00 \pm 0,92^{\mathrm{a}}$ & $\mathrm{P}<0,05$ &
\end{tabular}

${ }^{1}$ Estatisticamente não significativo.

${ }^{2}$ Valores de referências para hemograma, leucograma e proteínas totais de bovinos segundo Meyer e Harvey (2004).

Por meio da técnica de PCR 36 (75,00\%), bovinos leiteiros foram confirmados com a infecção por A. marginale e submetidos aos protocolos terapêuticos descritos, em que se observou que, no tempo 1 (cinco dias após o tratamento), a enrofloxacina $10 \%$ mostrou-se mais eficaz que os outros princípios ativos, reduzindo a quantidade do microrganismo na corrente sanguínea dos bovinos (Tab. 2). Entretanto, no tempo 2 (10 dias após o tratamento), não foi possível verificar o mesmo efeito. Com relação aos três protocolos, todos 
apresentaram efetividade contra a infecção por $A$. marginale, ao longo dos tempos dos tratamentos, sendo a enrofloxacina $10 \%$ com $\mathrm{P}=0,0009$, o cloridrato de oxitetraciclina $20 \%$ com $\mathrm{P}=0,0030$ e o dipropionato de imidocarb $1 \%$ com $\mathrm{P}=0,013$. Já na comparação entre os três grupos, por meio do teste exato de Fisher (Tab. 2), verificou-se diferença significativa entre o tratamento da enrofloxacina $10 \%$ e do dipropionato de imidocarb $1 \%$, apresentando $\mathrm{P}=0,0472$, quando se avaliou a prevalência de animais positivos para o A. marginale, após cinco dias de tratamento. Isso evidencia que a redução da infecção pelo $A$. marginale foi mais rápida no tratamento com enrofloxacina $10 \%$ (Fig. 1) em comparação com os outros dois tratamentos. No entanto, quando se fez a mesma análise na terceira coleta, não houve diferença significativa entre os tratamentos (Tab. 2), embora seja visível (Fig. 1) a tendência na diminuição da prevalência de positivos ao longo do tratamento com imidocarb e oxitetraciclina.

Tabela 2. Prevalência de animais positivos para anaplasmose ao exame da reação em cadeia pela polimerase (PCR), durante e após o tratamento com dipropionato de imidocarb (1\%), enrofloxacina (10\%) e cloridrato de oxitetraciclina (20\%), em bovinos leiteiros naturalmente infectados por $A$. marginale no município de Douradina, Paraná, Brasil, 2012

\begin{tabular}{ccccccccc}
\hline Tempo & Tratamento & $\mathrm{n}$ & Positivos & $\%$ & Negativos & $\%$ & $\begin{array}{c}\text { Exato de } \\
\text { Fisher }(\mathrm{p})^{*}\end{array}$ & $\begin{array}{c}\text { teste } \mathrm{Q} \\
(\mathrm{p})^{* *}\end{array}$ \\
\hline 0 & DI & 13 & 13 & 100,0 & 0,0 & $0,0^{\mathrm{b}}$ & - & $\mathrm{p}=0,0130$ \\
& Ef & 11 & 11 & 100,0 & 0,0 & $0,0^{\mathrm{b}}$ & - & $\mathrm{p}=0,0009$ \\
& CO & 12 & 12 & 100,0 & 0,0 & $0,0^{\mathrm{b}}$ & - & $\mathrm{p}=0,0030$ \\
1 & DI & 13 & 8 & 61,54 & 5 & $38,46^{2 \mathrm{a}}$ & & \\
& Ef & 11 & 2 & 18,18 & 9 & $81,82^{1 \mathrm{a}}$ & ${ }^{1} \mathrm{p}=0,0472$ & \\
2 & CO & 12 & 6 & 50,00 & 6 & $50,00^{2 \mathrm{a}}$ & & \\
& DI & 13 & 6 & 46,15 & 7 & $53,85^{\mathrm{a}}$ & $\mathrm{ns}$ & \\
& Ef & 11 & 5 & 45,45 & 6 & $54,55^{\mathrm{a}}$ & $\mathrm{ns}$ & \\
& CO & 12 & 4 & 33,33 & 8 & $66,67^{\mathrm{a}}$ & $\mathrm{ns}$ & \\
\hline
\end{tabular}

* Para comparação entre os tempos e os tratamentos; números desiguais indicam diferença estatística significativa $\left({ }^{1} \mathrm{e}^{2}\right)$.

**Para comparação das prevalências de positivos e negativos antes e após o tratamento; letras desiguais indicam diferença estatística significativa $\left({ }^{\mathrm{a}} \mathrm{e}^{\mathrm{b}}\right)$.

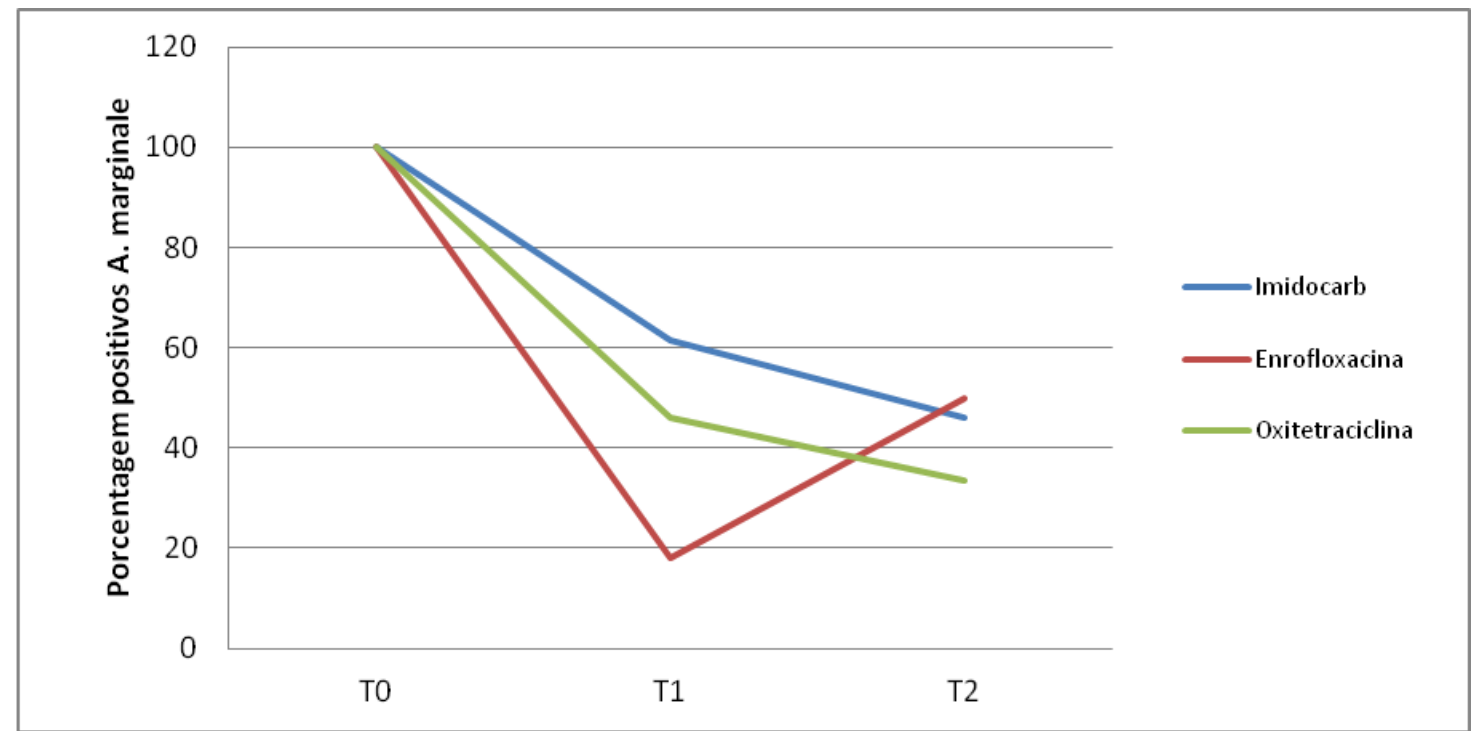

Figura 1. Evolução da redução da rickettsemia (\%), após o tratamento com dipropionato de imidocarb (1\%), enrofloxacina (10\%) e cloridrato de oxitetraciclina (20\%), em bovinos leiteiros positivos na reação em cadeia pela polimerase (PCR) para A. marginale no município de Douradinha, Paraná, Brasil, 2012. 


\section{DISCUSSÃO}

Segundo Gotze et al. (2008), o uso de oxitetraciclina, na dose de $20 \mathrm{mg} / \mathrm{kg}$, apresentou segura eficácia no tratamento de anaplasmose em vacas leiteiras em produção. Esse resultado se confirma no presente trabalho, porém, neste estudo, pode-se verificar maior eficácia da enrofloxacina. De acordo com Facury-Filho et al. (2012), a eficácia da oxitetraciclina no tratamento de anaplasmose depende diretamente do tempo de administração, bem como da concentração administrada do antibiótico, que precisa estar acima da concentração inibitória mínima, para ter efeito sobre o agente patogênico. Nesse sentido, a OIE (Organização Mundial de Saúde Animal, 2010) recomenda, em animais persistentemente infectados, a administração de $22 \mathrm{mg} / \mathrm{kg}$ ao dia de oxitetraciclina por via intravenosa, durante cinco dias consecutivos (Coetzee et al., 2005). Em animais experimentalmente infectados, estes mesmos autores verificaram que, após 60 dias, o tratamento com oxitetraciclina, em doses de 30 e $22 \mathrm{mg} / \mathrm{kg}$, não foi efetivo para eliminar a infecção persistente. No entanto, Atif et al. (2012) utilizaram esse protocolo objetivando a quimioesterilização de bovinos naturalmente infectados e mantiveram apenas 86,67\% (13/15) dos animais tratados, livres da infecção, 56 dias pós-tratamento ao teste de ELISA. Dessa forma, não só a posologia deverá ser considerada mas também a possibilidade de resistência à oxitetraciclina pelo microrganismo.

Quanto ao imidocarb, Akhter et al. (2010) relatam que o medicamento, administrado em dose de $3 \mathrm{mg} / \mathrm{kg}$ em duas injeções intramusculares, foi capaz de eliminar a infeçcão. Também, Roby e Mazzola (1972) relatam a quimioesterilização com duas doses a intervalos de 14 dias em dose de $5 \mathrm{mg} / \mathrm{kg}$. No entanto, sabese que, em doses maiores, efeitos colinérgicos podem ser observados, tais como: salivação, dispneia e diarreia (Adams e Corrier, 1980). Neste estudo, essas reações adversas não foram observadas. Já quanto à eficácia, apenas 53,5\% dos animais positivos tornaram-se negativos após o tratamento. Al Saad (2007) verificou resultados superiores do imidocarb contra a anaplasmose, em posologia de $3,5 \mathrm{mg}$, repetido com $48 \mathrm{~h}$, sobre a oxitetraciclina em dose de $20 \mathrm{mg} / \mathrm{kg}$, também repetida com $48 \mathrm{~h}$.
A enrofloxacina, um antimicrobiano bactericida de amplo espectro de ação, tem sido utilizada como terapia alternativa contra a anaplasmose. Altas concentrações plasmáticas em curto período de tempo determinam uma ação bactericida mais rápida (Kaartnen et al., 1995). Estes autores encontraram redução significativa na rickettisemia com aplicação em dose única de $7,5 \mathrm{mg} / \mathrm{kg}$. Facury-Filho et al. (2012) encontraram resultados semelhantes ao utilizarem a mesma posologia em bovinos experimentalmente infectados. Esses achados corroboram os resultados encontrados no presente trabalho, pois a enrofloxacina teve ação mais rápida em reduzir a prevalência de infecção em relação ao imidocarb e à oxitetraciclina (Fig. 1). Os resultados obtidos com o tratamento com dipropionato de imidocarb, enrofloxacina e oxitetracicilina foram semelhantes àqueles descritos na literatura e capazes de reduzir significativamente a prevalência de infecção dos animais deste estudo até o $10^{\circ}$ dia após o início do tratamento. Apesar de a enrofloxacina ter sido consideravelmente mais eficaz no início, o tratamento com oxitetraciclina manteve a menor prevalência de animais positivos ao final do estudo, seguido daquele com dipropionato de imidocarb. Embora essas diferenças não tenham sido significativas, os dados indicam a possibilidade de se iniciar o tratamento com a enrofloxacina associada com a oxitetraciclina ou com o dipropionato de imidocarb, com o intuito de se controlar melhor a doença no início e de se manter a efetividade por um período mais prolongado contra o parasito. De maneira mais abrangente, poderá constituir um protocolo interessante para que, juntamente com estratégias de controle dos insetos e carrapatos, diminua-se a prevalência da doença.

A anemia é o principal sinal de anaplasmose, com redução do hematócrito, que também pode ser alterado pela exposição ao risco sem medicação. A doença pode se apresentar na forma aguda, superaguda, leve ou crônica (Martins e Corrêa, 1995). Os sinais observados consistem de anemia hemolítica, icterícia, dispneia, taquicardia, febre, fadiga, lacrimejamento, sialorreia, diarreia, micção frequente, anorexia, perda de peso, aborto, às vezes agressividade (Barbet, 1995). Nos animais diagnosticados como positivos neste estudo, os sinais mais frequentemente encontrados foram perda de peso e mucosas hipocoradas, o que 
permite classificar como sendo a forma leve ou crônica da doença, que tem um maior potencial para manutenção e propagação da doença no rebanho, além dos prejuízos econômicos com a diminuição na produção.

Yoshirara et al. (2003) sugerem que a região noroeste do Paraná apresenta-se como área de instabilidade enzoótica, em que as condições climáticas não são totalmente favoráveis ao desenvolvimento do carrapato, porém possibilitam a ocorrência de infestações temporárias em população de risco (Arteche, 1992). Os bezerros que se infectam nos primeiros dias de vida, em regiões onde o carrapato está presente durante o ano todo, apresentam maior resistência devido à absorção de anticorpos colostrais, à imunidade celular e à presença de fatores séricos de resistência (Corrier e Guzman, 1977). Segundo Ristic (1960), os animais mais jovens ainda apresentam soro e hemoglobina fetal, o que prejudica parcialmente a multiplicação do agente no sangue, além de determinar maior atividade eritropoiética da medula óssea.

A imunidade conferida contra A. marginale é de duração variável e de origem tanto humoral quanto celular. $\mathrm{Na}$ anaplasmose, há evidência de resposta autoimune durante a fase aguda, parcialmente responsável pela anemia (Carson e Buening, 1979). Os animais utilizados neste estudo, por serem autóctones, provavelmente apresentavam resistência à infecção pelo $A$. marginale, manifestando a forma leve da doença, o que também pode explicar a insignificante diferença nas análises do hemograma e leucograma entre os animais infectados e não infectados pelo A. marginale (Tab. 1). Entre as proteínas plasmáticas, a albumina é a mais abundante. Devido ao grande tamanho da molécula, normalmente é retida nos capilares, entretanto ela é a primeira proteína a ser perdida durante as injúrias teciduais (Kaneko, 1989). Um quadro de hipoalbuminemia auxilia o clínico a limitar o seu diagnóstico diferencial de uma determinada enfermidade. Em paciente acometido por A. marginale, Teruel et al. (2009) verificaram, assim como neste trabalho, níveis mais baixos de proteínas plasmáticas.

\section{CONCLUSÃO}

Por meio do presente trabalho, pode-se concluir que os três antimicrobianos avaliados, dipropionato de imidocarb, enrofloxacina e cloridrato de oxitetraciclina, tiveram resultado positivo na redução da infecção por $A$. marginale em bovinos leiteiros naturalmente infectados. Porém, a enrofloxacina apresentou uma resposta mais rápida, mostrando-se mais eficaz, quando comparada aos outros dois antimicrobianos, nos primeiros cinco dias de tratamento. Após cessado o tratamento, entretanto, o imidocarb e a oxitetracilina mantiveram a tendência em diminuir a prevalência de animais positivos ao longo do estudo. Nenhum protocolo foi capaz de combater a infecção em todos os animais de cada grupo até o $10^{\circ}$ dia após o início do tratamento. Estudos deverão ser direcionados com tratamento quimioterápico combinado com outras estratégias de manejo, com o objetivo de reduzir os índices de infecção crônica, já que esta é a principal causa de manutenção e propagação da doença nos rebanhos.

\section{AGRADECIMENTOS}

Ao Instituto de Pesquisa e Ambiência Científica (IPEAC) - Unipar, pelo apoio financeiro; à Universidade Estadual de Londrina (UEL), pelo auxílio na execução das análises da PCR.

\section{REFERÊNCIAS}

ADAMS, L.G.; CORRIER, D.E. A study of the toxicity of imidocarb dipropionate in cattle. Res. Vet. Sci., v.28, p.172-177, 1980.

AKTHER, N.; LAL, C.; GADAHI, J.A. et al. Efficacy of various antiprotozoal drugs on bovine babesiosis, anaplasmosis and theileriosis. Vet. World, v.3, p.272274,2010

AL SAAD, K.M. Comparative study of imidocarb, oxytetracycline $2 \%$ and diminazine in treatment of bovine anaplasmosis. Iraqi. J. Vet. Res., v.21, p.307316, 2007.

ARTECHE, C.C.P. Imunoprofilaxia da tristeza parasitária bovina (TPB) no Brasil. Uso de cepas atenuadas da Babesia spp e de cepa de Anaplasma. Hora Vet., v.11, p.39-42, 1992.

ATIF, F.A.; KHAN, M.S.; KHAN, M.A. et al. Chemoteherapeutic efficacy of oxytetracycline, enrofloxacin and imidocarb for the elimination of persistente Anaplasma marginale infection in naturally infected sahiwal cattle. Pakistan J. Zool., v.44, p.449456, 2012. 
BARBET, A.F. Recent developments in molecular biology of anaplasmosis. Vet. Parasitol., v.57, p.4349, 1995.

BIRKENHEUER, A.J.; LEVY, M.G.; BREITSCHWERDT, E.B. Development and evaluation of a seminested PCR for detection and differentiation of Babesia gibsoni (Asian genotype) and $B$. canis DNA in canine blood samples. J. Clin. Microbiol., v.41, p.4172- 4177, 2003.

BOOM, R.; SOL, C.J.A.; SALIMANS, M.M.M. et al. Rapid and simple method for purification of nucleic acids. J. Clin. Microbiol, v.28, p.495-503, 1990.

CARSON, C.A.; BUENING, G.M. The immune response of cattle to live and inactivated anaplasma vacines and response challenge. J. S. Afr. Vet. Assoc., v.50, p.330-331, 1979

COETZEE, J.F.; APLEY, M.D.; KOCAN, K.M. et al. Comparison of three oxytetracilcine regimens for the treatment of persistent $A$. marginale infections in beef cattle. Vet. Parasitol., v.127, p.61-73, 2005.

CORRIER, D.E.; GUZMAN, S. The effect of natural exposure to Anaplasma and Babesia infections on native calves in an endemic area of Colombia. Trop. Anim. Health Prod, v.9, p.47-51, 1977.

FACURY-FILHO, E.J.; CARVALHO, A.U.; FERREIRA, P.M. et al. Effectiveness of enrofloxacina for the treatment of experimentally-induced bovine anaplasmosis. Rev, Bras. Parasitol. Vet., v.21, p.3236, 2012.

FELSHEIM, R.F.; CHÁVEZ, A.S.; PALMER, G.H. et al. Transformation of Anaplasma marginale. Vet. Parasitol., v.167, p.167-174, 2010.

GOTZE, M.M.; NIZOLI, L.Q.; SILVA, S.S. et al. Efeitos da oxitetraciclina na recomposição do hematócrito de vacas leiteiras durante surto de anaplasmose bovina. Rev. Bras. Parasitol. Vet., v.17, p.92-95, 2008.

KAARTINEN, L.; SALONENE, M.; ALLI, L. et al. Pharmacokinetics of enrofloxacin after single intravenous, intramuscular and subcutaneous injections in lactating cows. J. Vet. Pharmacol. Ther., v.18, p.357-362, 1995

KANEKO, J.J. Clinical biochemistry of domestic animal. San Diego: Academic, 1989. 932p.

KOCAN, K.M.; FUENTE, J.; BLOUIN, E.F. et al. The natural history of Anaplasma marginale. Vet Parasitol., v.167, p.95-107, 2010.
MARTINS, J.R.; CORRÊA, B.L. Babesiose e anaplasmose bovina: aspectos destas enfermidades. Pesqui. Agropecu. Gaucha, v.1, p.51-58, 1995.

MELO, S.A.; CARVALHO NETA, A.V. Estratégias de controle na babesia bovina. Beef Point, 2009. Disponível em: <http://www.beefpoint.com.br/ radares-tecnicos/sanidade/estrategias-de-controle-nababesia-bovina-51756/> . Acessado em: 26 fev. 2014.

MEYER, D.J.; HARVEY, J.W. Veterinary laboratory medicine: interpretation \& diagnosis. 2.ed. Philadelphia: Saunders, 2004. 351p.

MOURA, A.B.; VIDOTTO, O.; YAMAMURA, M.H. et al. Studies on the Anaplasma marginale THEILER, 1910 infection in Boophilus microplus (CANESTRINI, 1887) using "nested" PCR. Rev. Bras. Parasitol. Vet., v.12, p.27-32, 2003.

OIE - Organização Mundial de Saúde Animal. Código sanitário para animais terrestres. Paris, 2010 Disponível em: <http://web.oie.int/esp/normes/ mcode/es_chapitre_1.11.1.pdf. $>$. Acessado em: 10 set. 2014.

PEREIRA-MAIA, E.C.; SILVA, P.P.; ALMEIDA, W.B. et al. Tetracyclines and glycylcyclines: an overview. Quim Nova, v.33, p.12-19, 2010

RAMOS, C.A.N.; RAMOS, R.A.N.; ARAÚJO, F.R. et al. Comparação de nested-PCR com o diagnóstico direto na detecção de Erlichia canis e Anaplasma platys em cães. Rev. Bras. Parasitol. Vet., v.18, p.5862, 2009.

RISTIC, M. Anaplasmosis. Adv. Vet. Sci., v.7, p.111192, 1960

ROBY, T.O.; MAZZOLA, V. Elimination of the carrier state of bovine anaplasmosis with imidocarb. Am. J. Vet. Res., v.33, p.1931-1933, 1972.

TERUEL, G.M.; SANTOS, M.S.P.; GOMES, I.T. et al. Anaplasmose bovina: relato de caso. Rev. Cient. Elet. Med. Vet., v.7, 2009.

VIDOTTO, O.; MARANA, E.R.M. Diagnóstico em anaplasmose bovina. Cienc Rural, v.31, p.361-368, 2001.

YOSHIHARA, E.; VIDOTOO, O.; YAMAMURA, M.H. et al. Studies of natural infection with Anaplasma marginale in nelore cattle in the Umuarama municipality, Paraná state, Brazil. Rev. Bras. Parasitol. Vet., v.12, p.21-26, 2003. 